\title{
Participatory action research, strengthening institutional capacity and governance: Confronting the urban challenge in Kampala
}

\section{Commonwealth Journal of Local Governance \\ Special Issue March 2010: \\ Commonwealth Local Government Conference \\ Freeport, Bahamas, May 2009 \\ http://epress.lib.uts.edu.au/ojs/index.php/cjlg}

\author{
Shuaib Lwasa PhD \\ Department of Geography \\ Makerere University

\section{Gilbert Kadilo} \\ Department of Mass Communication \\ Makerere University
}
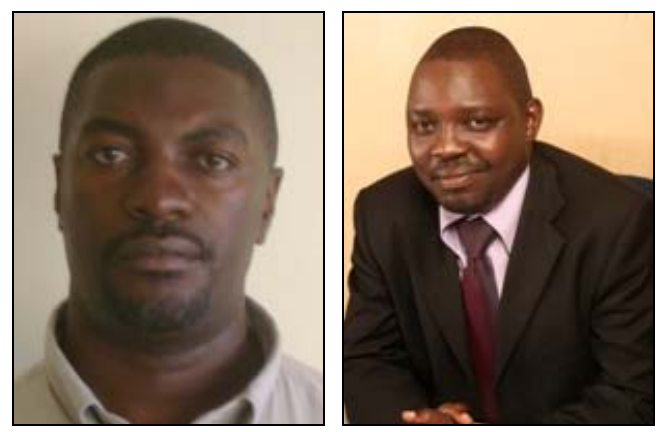

\section{Abstract}

Urban governance presents the most daunting and challenging task for sub-Saharan African countries in this century (Rakodi, 1997: 3; Rakodi, 2001; 5; McGill, 1988; 6). Africa is urbanizing faster than any other region. The level of urbanization stands at $39.1 \%$, with annual rates of growth ranging between $8 \%$ and $13 \%$. It is estimated that by 2025 half of the African population will be urban. This demographic shift, particularly in the sub-Saharan region, presents major problems for urban management. Although urban management programs of infrastructure development, financial management, economic development, environmental planning, spatial development mechanisms and social services provision continue to be enhanced, there is a mismatch between the program outcomes and need. Due to this shortfall, alternative strategies have been sought but with little documented evidence of successes, failures and lessons because of limited evaluation. The importance of research-informed policy is underscored by the apparent disconnect between actors in the urban field. These actors include city managers, researchers, political leaders and most important, communities. The latter are often disregarded yet they largely influence the development path and shape the fabric of 
urban space. Even where communities are engaged, they exert less influence than other actors on urban policies and programs. This paper examines how participatory action research is changing the relationships between researchers, communities and city authorities in a search for alternative approaches to address urban poverty and environmental challenges in Kampala - in particular service delivery, solid waste management and flood control. Based on an action-research and development project conducted in Kampala since 2006, there is evidence that communities can be galvanized not only to design solutions to their problems, but also to engage with city authorities through information sharing platforms about their needs and thus bolster outcomes of urban development programs through improved governance.

Keywords: Participatory action research, Informed policy, Urban communities, Urban poverty, Urban environment.

\section{Introduction}

Experiences in many developing countries suggest that the level and quality of urban services and infrastructure does not match the growth of populations in their cities (Brockerhoff, 2000: 1; UN-Habitat, 2005: 14; UN-Habitat, 2008: 15). Financial, management and technical challenges continue to limit the capacity of urban governments to provide adequate services and infrastructure (UNECA, 2007 31). As a result, the quality of life for urban populations remains characterized by poor environmental conditions, poor sanitation and health problems, which dominate the agendas of local governments. These inadequacies have also led to a polarization of urban populations, with large proportions of city residents (often the poor) living with very limited basic services amidst scattered neighborhoods with relatively adequate services (Rakodi, 1997: 25; Simon, 1992: 21; UN-Habitat, 2008: 15). Targets 7, 10 and 11 of the United Nations Millennium Development Goals (MDGs) emphasize among other things the need to tackle urban infrastructure through pro-poor urban service delivery in order to reduce poverty in cities of the developing world.

In Uganda, municipalities have grappled with the problems of service delivery, particularly solid waste management, with little success due to the dynamics of urban systems in terms of population, governance and management challenges. The initial response to these challenges was a project-oriented sectoral approach to urban development, with the establishment of specific public works authorities to finance and 
install infrastructure. While these proliferated, coordination problems emerged, coupled with little attempt to ensure ongoing operation and maintenance by the local governments. In the face of this failure of local governments and public works authorities to cope with the problems of rapid growth, the response has been advocacy for a multitude of approaches including decentralization, local community organization, participation, self-help and public-private partnerships (WBG, 2001: 33; Jain, 2004: 34; MoLG, 2001: 35). More recently privatization of urban service and infrastructure provision has been implemented and shaped by different experiences, taking on many forms including monopoly, competition, management contracts and community-based infrastructure provision. For example, the World Bank Group has proposed community contracting (where appropriate) and this is envisaged to be a double-edged in terms effect, of providing employment and improving services in poor communities (WBG, 2001: 33). Most of these approaches have embedded governance improvement tenets but there is little evidence of improvement of urban governance systems which are still technocratic and top-down with skewed power relations (Rakodi, 2001: 32), leading to polarization of urban communities. Privatization, for example, has improved service delivery (Rugadya, 2006: 36) but despite this improvement, it has also created problems of less service coverage, unhealthy competition among providers, and inflated service costs. Some of these problems (ie cost inflation) are created at the outset during the tendering process, leading to end-pipe problems such as accumulated solid wastes and inaccessible potable water, as well as conspicuously different neighborhoods in terms of 'haves' and 'have nots'.

This paper examines how the knowledge-base from action research is galvanizing information exchange platforms around which urban actors including communities, researchers and policy makers can engage to improve governance and service delivery in Kampala. An information exchange platform here is taken as a network of researchers, communities, organizations and government agencies - either formal or informal through which research is undertaken, practices evaluated and experiences shared across the diverse stakeholders. The network operates on a premise that knowledge will be generated and can be accessible to many actors in urban development. Although there are several requirements for improved urban governance, information and knowledge are key, and research shows that much useful knowledge is scattered rather than pooled to provide answers to the burgeoning urban challenges (IEG, 2008: 40). 


\section{Urban management challenges and responses}

This section sets the context and theoretical framework, while positioning the argument regionally in relation to the gaps between urban management needs and the policy response. The outcomes of urban management in sub-Saharan Africa, and Uganda in particular, have become unpredictable (Egbu, 2006: 7; Arimah, 2000: 11). Planned outcomes are often not achieved because cities develop as a result of millions of independent consumption and production decisions by different individuals, organizations and groups. But the perpetual financial and institutional capacity challenges have also continued to curtail sustainable urban development (McGill, 1988: 42). In Uganda, there is evidence of positive outcomes of urban management with increased and innovative urban service delivery. But this success is scattered in a few areas creating isolated pockets of well serviced and developed neighborhoods and/or industrial parks and transportation corridors (TAHAL, 2005: 37) amidst widespread impoverishment. Successes in urban service delivery are also evident in numerous secondary towns dotted around the country, where somewhat more responsive delivery processes are still in place and followed by the town managers and developers. But the greater part of urban development throughout the towns and major city of Uganda is occurring largely informally with inadequate services.

The failures of planning, an arm of urban management in Uganda, can be attributed to many factors including lack of municipal resources and regulatory enforcement, land issues, and inadequate human resource capacity, but governance and institutional aspects as well as knowledge management have of late become outstanding (Lwasa, 2006: 36, Peirce, 2008: 41). As Pierce noted, the time for action is past and innovative urban research is necessary for sustainable urban development. Yet the major players in urban growth - those carrying out development - generally have not been well linked to the values of planning and orderly development nor to the knowledge bases to guide development. The fundamental basis for urban planning and management is that development should meet the needs and aspirations of the population, or enable people to innovate to meet their own needs. It is therefore important to recognize the differing needs and aspirations of a diverse society and population, with possibly differing locally defined values (UNECA, 2007: 31). 


\section{Promoting pro-poor urban service delivery}

Despite six decades of fast-paced development in Kampala, the poor form the biggest proportion of the urban population in Uganda, thereby creating a high demand for urban services. As noted by ILRI about $40 \%$ of the population of Kampala is in the ranks of the urban poor (ILRI, 2002: 43). These people are contributing greatly to the urban economy through the informal sector, but remain marginalized in terms of urban services. Due to problems of affordability, non-cooperation and the difficulty in organizing residents of poor neighborhoods, a large proportion of Kampala's population remains without services (REEV, 2008: 38; Rugadya, 2006: 36; Sengendo, 1997: 22).

UN-Habitat has been at the forefront of efforts to promote pro-poor urban service delivery in sub-Saharan Africa. Pro-poor urban service delivery has three main elements: first, it is service delivery that enables the poor to be recognized as citizens with a social right to urban services; second, it is a system that includes poor neighborhoods into the planning of areas for expansion and extension of urban services; and third, it is a system that involves innovative standards and procedures for urban service delivery (UNHABITAT, 2004). These three elements would make a system that enables accessibility and makes services affordable: accessible in the sense that people in poorer neighborhoods would have services such as water in quantities and of quality that suits their needs; affordable in that the quantity and quality of services available to individuals or households would not be reduced due to price. The cost of services charged to the urban poor should as far as possible enable all people to access the service. Experiences in Kampala indicate that there is a knowledge gap regarding the ways and means of making urban service delivery pro-poor.

Current responses to the overwhelming needs of the urban poor are characterized by ad hoc approaches to service delivery. An example is the reactionary response to needs triggered by catastrophes or disasters (Prasad, 2009: 2). Although the causes of health epidemics such as cholera are known and can be tackled by provision of basic services such as water and sanitation, there is a repeated reactionary response to the epidemics which recur annually as a result of high rainfall. This reactionary approach has taken root in Kampala and ad hoc committees are established to deal with predictable disasters. At the same time, many individual urban dwellers provide urban services by themselves with or without municipal support due to the gap between local government service delivery and need. Thus, individual ingenuity and community action are also helping 
urban communities cope through such 'self-provisioning' where urban communities mobilize human, financial and other resources to provide services such as extension of water supply, urban drainage utilities, solid waste management and sometimes road maintenance.

Such experiences in urban service delivery, and efforts for improved urban neighborhoods, are inherently disjointed with many different actors involved: civil society organizations, individual, households and development aid bodies. But knowledge is important in driving the ingenuity and thus knowledge platforms become an important tool for enabling these actors to engage with each other on development issues and popularize best practices.

\section{Urban local authorities and development planning}

Through decentralization policies in Uganda, local governments have been mandated to provide services to the population. The Local Government Act 1995 outlines the mandate of town councils and municipalities in respect of the services they are supposed to deliver to the population, including road opening and maintenance, street lighting, garbage collection, drainage installation and other services. The Act is implemented in conjunction with others including the Town and Country Planning Act 1964, Public Health Act, the Land Act 1998 and National Environment Management legislation. Decentralization has devolved administrative and managerial powers to local governments and through a national capacity building program, local governments have been equipped with toolkits for planning and development including services planning and delivery. Three-year development plans form the basis of budgeting and annual work plans, providing an outline of the mid-term strategic goals of the local government and reflecting the resource base. The focus is on allocation of resources, mainly financial, increased productivity, and improvement in socio-economic welfare and poverty reduction (KCC, 2005: 12).

Until the year 2000 when 3-year development plans were launched, planning occurred on a sectoral basis through the various line ministries and departments within local governments. The new 'bottom-up' approach to development planning has been rolled out through the Local Government Development Program (LGDP). Local Governments prepare 'investment plans' with estimates for projects which are identified from the lowest administrative unit of a parish through to sub-county level. Community 
identification of projects, community contribution to project investments, and local decision making concerning the allocation, prioritization and implementation of projects is emphasized in this approach. The motivation for this new approach is three pronged: first, the persistence of poverty and now urban concentrated poverty; second, the concern that foreign direct investments have not been successful in reduction of poverty; and third, the emergence of new partnerships for pursuance of development.

The LGDP has provided the platform for engagement of a range of urban development actors, especially local communities and municipal authorities, but until now a key category of actors has been missing, namely researchers. Research is essential to inform the planning cycle and prioritization of investment projects (Peirce, 2008: 41). Although some research is done currently through local government planning departments, this is inadequate in identifying the key issues and entry points for poverty eradication, let alone the fundamentals of development programs.

Research shows that there is still more that can be done to improve outcomes of development programs. Participatory action research shows that the actors are yet to be fully engaged and that knowledge utilization needs to be stepped up to improve service delivery (UNECA, 2007: 31). For example in the areas of environmental services such as water, waste management and sanitation, knowledge about alternative means for provision and improvement is yet to be integrated into urban local authority plans. The current focus on 'traditional' service provision (with strategies led by the private sector) is contributing to the polarization of urban communities. Procurement procedures emphasize private sector contracting without considering community contracting or building the capacity of existing community based organizations that would improve services and also generate jobs locally. Practical solutions do exist that would deliver multiple benefits, but they are scattered and little known. Knowledge exchange platforms are needed to galvanise improved service provision.

\section{The Kampala research project}

As noted above, urban service provision has remained largely a mandate of Kampala City Council (KCC), and is characterized by top-down relations that have for a long time put communities on the receiving end. Even with the emergence of newer forms of private sector-led service delivery, that sometimes include community-based organizations, the dominance of private firms is undoubted. 
Against this background, a participatory action-research project was initiated to identify alternatives for enhanced service delivery and to inform policy for reform and change in urban governance. The research sought to find practical solutions to the intertwining challenges of urban poverty and environmental distress. Also, as a component of the bigger study, the issue of platforms for exchanging information, good practices, lessons and networks was studied with an understanding that communication is the key to propelling interactions between researchers, communities, policy makers and city managers for improved governance. This is because of the undoubted importance of evidence-informed policy. Objectives were:

a) to conduct a situation analysis, identify existing communication channels, and collect proposals for improved information flow among the urban actors

b) to develop a communication strategy that would encourage networking and information sharing among stakeholders utilizing existing communication channels

c) to initiate a local platform involving policy makers, researchers and communities in Kampala that would enable engagement and dialogue on urban management.

The study was conducted in the Makerere II, Bwaise III and Kasubi Parish administrative zones within Kawaala-Kasubi, a densely populated neighbourhood including both hill slopes and low-lying land. The neighborhood has an estimated population of 40,000 and a density of 141 persons per hectare. It is one of the 'poverty hot-spots' characterized by informal settlements with limited services and infrastructure (ILRI, 2002: 43). The neighborhood experiences several environmental burdens, including accumulated solid wastes, poor sanitation and flooding. ${ }^{1}$

The neighborhood has been a focus of urban environmental policy debate among policy makers and Kampala City Council. The challenges experienced in the neighborhood are also grounds for testing the urban governance system, how the system responds to the problems, where and how knowledge is acquired as well as the decision making processes involved. The study employed qualitative methodologies including focus group discussions (FGDs), field observation and in-depth interviews. A total of eight

1 Flooding spreads organic and inorganic wastes and contaminants, and also makes impassable the narrow earth roads that connect this area. 
FGDs were conducted and 70 community members participated. ${ }^{2}$ Field observations complemented FGDs on important issues around which engagement with policy makers and researchers could be pursued. These issues included garbage management, health risks, constrained drainage flow and flooding. A total of four in-depth interviews with key partners were conducted. These included Kampala City Council (KCC) staff, Environmental Alert (EA), the Ministry of Agriculture, Animal Industry and Fisheries, and researchers. This allowed conversations on issues of planning for service delivery and involvement of different actors in decision-making. Interviews focused on the roles of different actors in urban service delivery and the communication process, and the channels used for communication with other partners and the target communities. An interview guide was used for each category of respondents.

In addition to the methods described above, follow-up activities were organized to get broader views from a wide spectrum of stakeholders in urban management. A series of information exchange activities such as city consultations, community days and roundtable meetings were organized to provide a platform for the actors to dialogue on urban governance systems and possible alternatives for improvement. These activities provided the rationale for improved knowledge exchange platforms, as well as information on changing institutional roles and engagement among actors.

\footnotetext{
2 The groups comprised two women groups, two youth groups and four mixed-sex groups. Each group included 8-10 participants.
} 


\section{RESEARCH and EVALUATION}

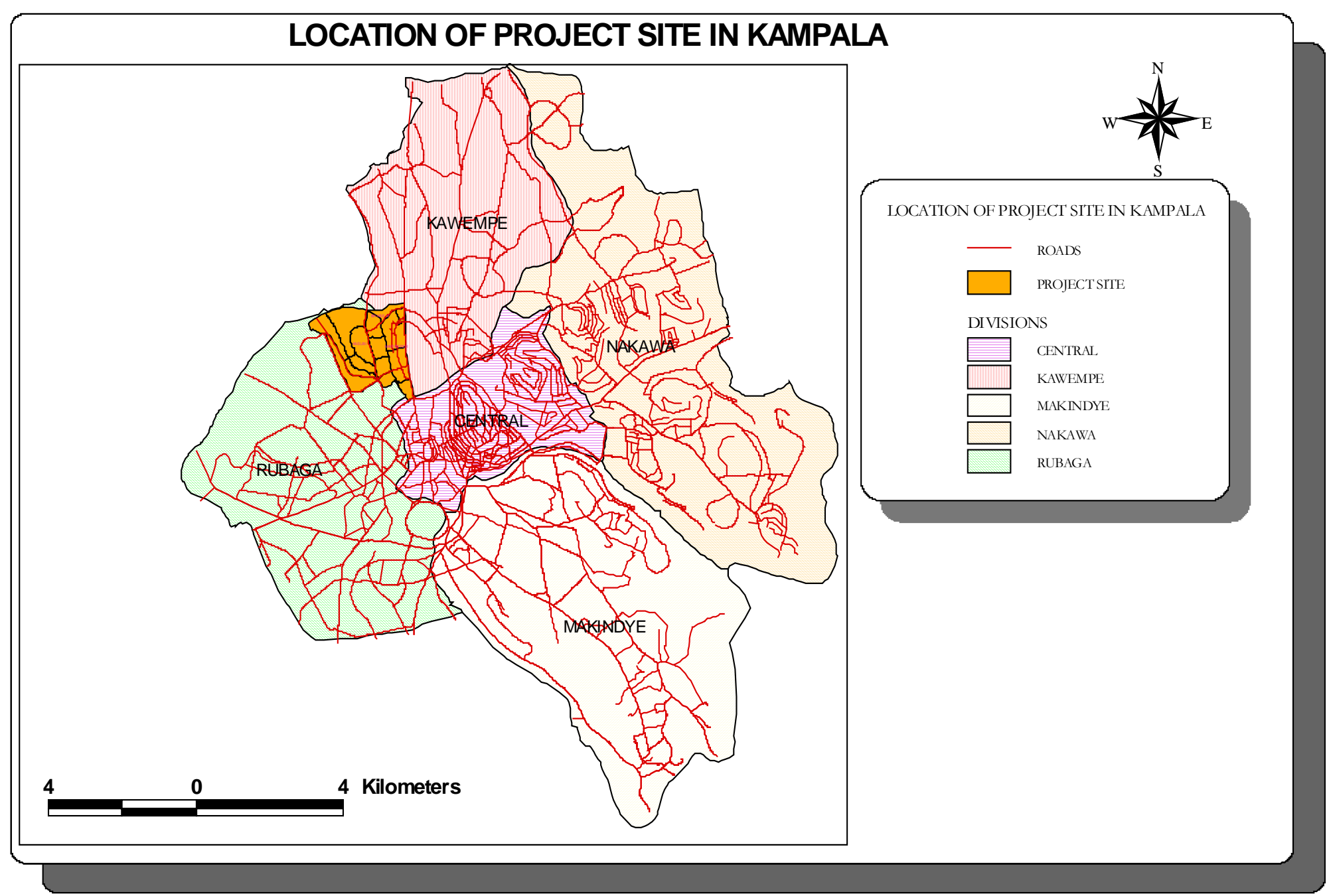

Figure 1. Location of project site in Kampala. 


\section{Findings}

\section{The disconnect among urban management actors}

Field data confirmed the need for better networking amongst the different actors in socioeconomic development, which has yet to be accomplished in urban areas. Civil society organizations have provided leadership in the field of networking and coordination and continue to work with municipal authorities to improve socio-economic wellbeing. They also relate well with researchers. However, relations between researchers and municipal authorities are a disconnect. Researchers have been called in to provide short-term expert assessment and advice, but without close engagement and deeper interaction on the underlying development issues. The disconnect is often manifest in claims on the part of municipal authorities that advice from researchers and or think-tanks is theoretical or nonpractical, while from researchers there is a view that municipal procedures and plans are unrealistic or not working (Rakodi, 2001: 32).

This situation results in the lack of a research-informed dialogue about urban development. The apparent disconnect hinders improved urban service delivery because it has curtailed the innovation that comes with sharing and exchanging information for the betterment of communities. Interviews with key informants showed that municipal authorities rarely participate in research oriented meetings to learn how they can improve service delivery. Likewise key informants from civil society organizations indicated that whereas they engage in knowledge generation, it is not regularly checked by researchers nor readily up taken by municipal authorities. Communities tend to be on receiving end, they feel isolated from other actors and thus continue to rely on what municipal authorities provide, especially when it is backed by legal and regulatory frameworks.

\section{Institutional issues in urban governance}

Urban governance relies on institutional, regulatory and legal frameworks, but it is important also to recognize the need for knowledge to support the process of decision-making. Governance is about more than the organizational structure (IADB, 2002: 39). It involves the 'rules of the game' that determine the nature of relations, authority and power in decision making. It is how municipal authorities and communities as well as the general public relate to each other to make development decisions. The level of response to community needs 
depends on both the laws, regulations and procedures in urban governance and the 'rules of the game' between the different actors. The key informant interviews were important in eliciting information regarding the relationships involved.

Two major institutional arrangements determine the engagement of the actors in urban service delivery in Kampala. These are firstly, the three year development plan processes, with associated annual work plans and budgets, and secondly, the strategic spatial plan for the city, which provides the overarching framework for development and allocation of resources in service delivery. The former follows the annual planning cycle including budget conferences held at lower levels of local government and is more directly accessible by urban actors. ${ }^{3}$ The intention of the budget process is to solicit investment priorities starting with the lowest administrative unit and proceeding through to the higher-level local government which, in this case, is the City of Kampala. Priorities are shuffled and rearranged based on criteria including resource availability and coverage. This bottom-up process has ushered in participatory prioritization and implementation of urban service delivery. Communities are guided through a series of steps on how to identify problems and projects for investment in the following financial year. In this way the public feels included in the planning and decision making. However, it has the drawback of progressively filtering priorities which subsequently leaves some communities not benefiting from investments. The filtering process and its consequences acts as a disincentive to engagement by communities, who see their power in decision making as illusory.

Also the process is linear in nature, without effective feedback and updating of priorities. Whereas budget conferences are held every year, little changes in terms of the selected investment projects to reflect the needs of the communities. Although one can argue that due to chronic urban poverty, basic needs are unlikely to change, the detail and approach to implementation of projects ought to be adjusted. This would reflect new knowledge on optimal alternatives for service delivery. For example, improved water supply in the study area has remained a perennial need - although standpipes were installed, these remained operational for only a short time due to factors such as apathy, personalization and elitist

${ }^{3}$ A budget conference is a meeting of stakeholders involving community representatives, managers, elected officials, development aid organizations and partners in development to discuss budget proposals for a local government area. 
capture. Another example is the collection of garbage which has been privatized. Whereas community based organizations were willing to provide the service (thereby creating a double benefit as discussed earlier), the law and regulations do not allow community contracting. It is recognized that community contracting is not the panacea for garbage problems but it is an alternative worth evaluating. Thus emerging knowledge and experience about processes and needs should be integrated into strategies for improvement, rather than urban authorities remaining stuck in the linear process and procedures that seem to be inflexible and less responsive to the needs of communities.

The second institutional arrangement is that of strategic spatial planning which occurs once in two or so decades. This process brings together the social, economic, governance and environmental aspects of urban development into an overarching spatial plan. The last strategic plan for Kampala was formulated in 1994 and expired in 2004, but was extended for two years. With the support of the World Bank, Kampala City Council is now formulating a new spatial plan for the metropolitan area. This process is also participatory and involves multi-level consultations with all stakeholders including communities. Following from the strategic plan, more detailed neighborhood plans are to be developed along with action plans for implementation. This is where community involvement in urban governance would have most impact. Urban communities are meant to participate in decision-making concerning the layout of the neighborhood and services to be provided.

Spatial planning and its implementation is where the most significant gaps exist between what is proposed and the reality. For example, through participatory action research, it has been established that decent housing is elusive to an estimated $40 \%$ of the residents in the study area due to overcrowding. Additionally, $90 \%$ of the residents rely on pit-latrines for sanitation. Implementing the spatial plan would mean an extension of sewer networks and water supply to the community, but this has not happened, nor have alternative means been adequately explored. Research showed that the planning and implementation process failed to adequately mobilize individuals, resources and ideas on how to improve service delivery. By contrast, action research has enabled realization of the community's potential by coupling the issues of urban poverty and environmental quality, and providing platforms for testing innovations and also learning by doing, galvanizing relations between the actors. It has 
sparked off partnerships in decision-making on priority activities and needed services. For example community bazaars displaying innovations, consultative meetings and community advocacy have improved communication with policy makers. KCC is now integrating some of the lessons from the project site into the strategic plan for services provision, and streamlining the relationships between the major actors to facilitate the bottom-up decision making process. There is also an indication of institutional strengthening and coordination for service delivery. KCC staff has now realized that alternative strategies can offer solutions for urban governance. Knowledge exchange has linked research to policy and this bridge is recognized as important in improving urban governance.

\section{Knowledge exchange platform}

The platform developed through the action research is represented schematically in figure 2. This participatory model provided the basis for enhanced stakeholder participation in improving urban governance and services provision. The model recognizes the importance of communication, which is at the centre of decision-making that involves communities, civil society organisations and other partners. It also sets clear roles and responsibilities for each of the actors. The platform is not merely about inclusiveness but stresses the importance of democratization, participation at all level, and reciprocal collaboration. Listening to what others say, respecting the counterpart's attitude and having mutual trust are inbuilt into the platform. The idea here is that development efforts should be anchored on people's capacity to discern their needs and to participate actively in transforming themselves. Thus local people become controlling actors or agents for development: they are active in self- and communal improvements, are engaged in dialogue rather than monologue, and are fully included in the democratic process (IEG, 2008: 40; MoFPED, 2000: 3; UNECA, 2007: 31). 


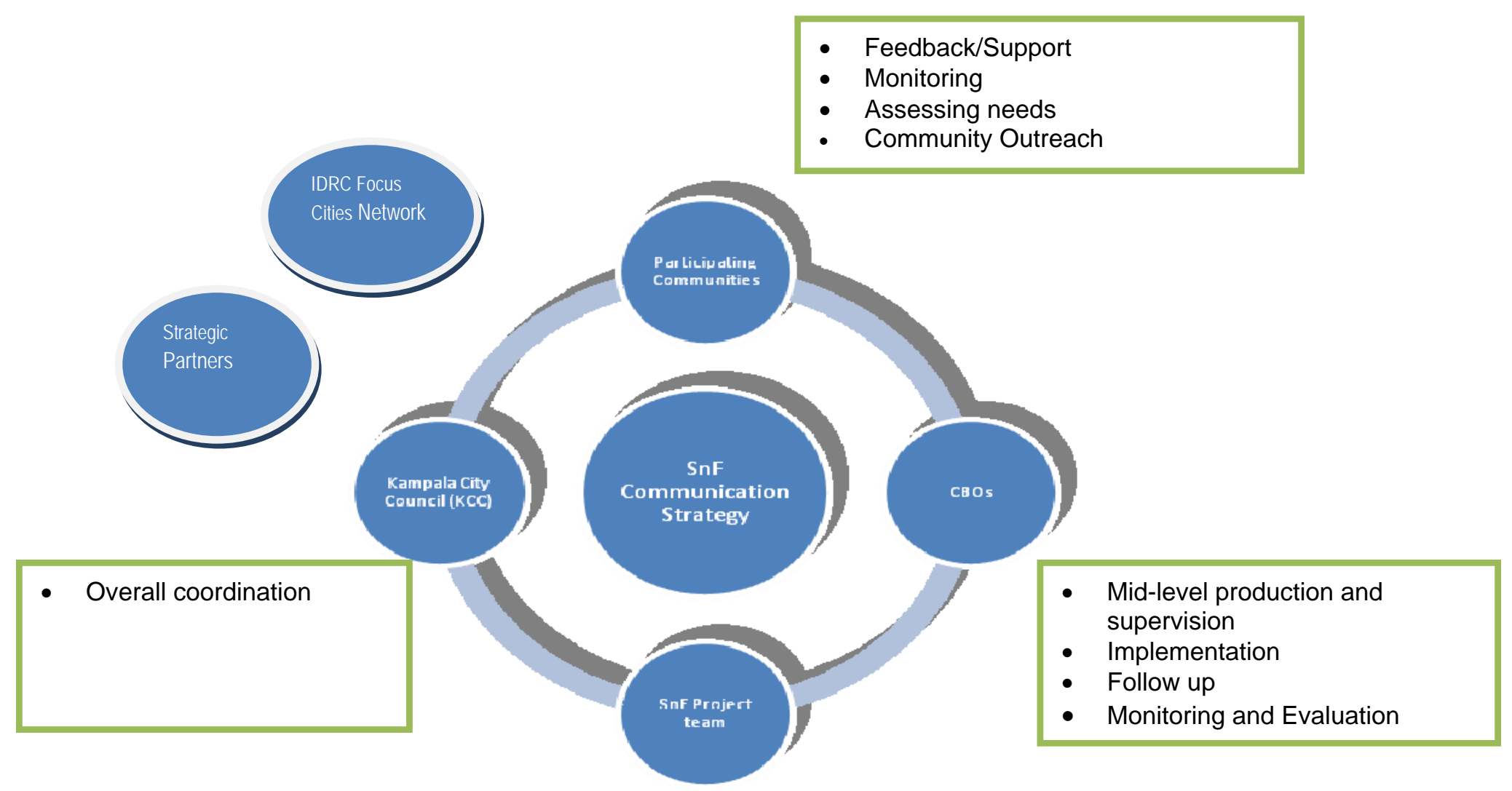

- Technical Direction

- Supervision

- Monitoring and Evaluation

- Follow up

Figure 2. Schematic representation of Knowledge Exchange Platform. 
The research revealed a dominance of formal communication through local leaders, community-based public announcements, posters and banners, coupled with reliance on electronic media (especially FM radios). But when it comes to real neighbourhood problems and solutions it is largely the informal channels which are important. An innovative solution is required to galvanize these informal channels of communication for cross-sectional sharing of information, best practices and knowledge. Community feedback mechanisms are needed to provide space for communities to voice their needs and also report how they are coping. Feedback mechanisms used in the action research have stimulated non-structured communication and engagement between urban actors thereby enhancing advocacy. For example dialogue meetings were held involving communities, councillors, researchers, technical managers and to some degree the media (Peirce, 2008: 41). The media's role is to continue informing the public about lessons learned. In these meetings, community members freely exchanged ideas about needs and solutions with councillors and municipal officials. Policy briefs were useful to provide readily available information to feed into municipal council debates about priorities and resource allocation in line with the community's needs. Another outcome is greater appreciation on the part of policy makers that researched information is useful for policy formulation and decision-making. Research protocols have been developed and implemented which has triggered demand for more research-based information.

\section{Community advocacy}

Another aspect of participatory action research which has paid off is strengthening community advocacy. Relations between communities and municipal authorities are often structured by regulatory frameworks that limit inclusive decision making. However the community in the project area now exhibits evidence of having been empowered to engage proactively with different actors. It now can advocate on an issue through community brainstorms in advocacy groups to identify areas for improvement, and then using new ways to dialogue with political leaders. For example, memos and advocacy documents have been developed regarding the issues of flooding and solid waste management, which has led to policy debates in the municipal council. Previously, advocacy involved representations to the area councillor and/or Member of Parliament but without documentation. Once a satisfactory 
response has been achieved, advocacy groups disband which dynamic is critical to building confidence in community.

Advocacy also involves promoting action by fellow community members. This is now practiced through community bazaars that are entirely organized by the community leaders and innovators. In these bazaars, innovators display (and put on sale) items made out of recycled materials and also new technologies such as energy briquettes which are reducing environmental problems. The influence of innovators on fellow community members is raising awareness and stimulating adoption of new ideas. Community members have also engaged in writing about their experiences, especially in regard to innovations but also other ideas. Through a periodic newsletter community members are now freely writing and encouraging their fellow members to adopt innovations and also to exercise behavioral change in respect to improving their environment and well-being. The newsletter reaches out to all actors in urban service delivery including policy makers, municipal authorities and the public. It is now the voice of the community and is already starting to generate interest from other communities and organizations. Through the newsletter and advocacy memos, the community is beginning to influence urban policy. Trials of community contracting for solid waste management have also been initiated.

\section{Conclusion}

The disconnect between researchers, policy makers, municipal authorities and communities is not something that will be resolved completely in the near future. However, as illustrated in the paper, self propelling knowledge platforms can offer significant improvements in improving information exchange, engaging communities, strengthening governance and stimulating innovation and creativity. Evidence also points to the knowledge exchange platform as a vehicle for promoting pro-poor urban service delivery that mobilizes local resources, enhances commitment on the part of the municipal authority, and promotes inclusive approaches. Steps have been taken as part of the research to ensure continuity of the knowledge platform beyond the life of the project, although this cannot be guaranteed.

However knowledge platforms and networks are just one part of achieving better urban policy responses. There are several other requirements for improved urban service delivery 
and development. The importance of institutional reform cannot be over-emphasized, while the need for greater capacity within urban local governments has also been underscored in many studies (Rakodi, 1997: 25; UN-Habitat, 2008: 15). Whereas there are signs of enhanced urban governance at community level from this local initiative, the sustainability of such changes remains in the hands of institutional readiness to mainstream the lessons for future urban governance. This would require re-engineering urban authorities to adopt alternative approaches to service delivery and adjusting regulatory frameworks. Policy reform and change is thus necessary, and building human resource capacity for this task is important.

In conclusion, the role of knowledge in improvement of urban service delivery and governance cannot be underestimated. Research-informed policy has the promise of transforming urban development, achievement of Millennium Development Goals and enabling urban actor engagement for enhanced governance. The lessons drawn in this paper need to be scaled-up and disseminated, but also reinforced and adapted based on the experiences of other actors and initiatives in urban management.

\section{Acknowledgements}

This work was carried out with the aid of a grant from the International Development Research Center, Canada (IDRC). Thanks also go to the Uganda project team partners including Environmental Alert, Kampala City Council, Makerere University, the International Center for Tropical Agriculture within the Ministry of Agriculture, Animal Industries and Fisheries, and the community of the Kasubi-Kawaala project area.

\section{References}

Arimah, C. B. and Adeagbo, D. 2000, 'Compliance with urban development and planning regulations in Ibadan, Nigeria’, Habitat International, vol. 24, pp. 279-294.

Bevan, P. and Sewaya, A. 1995, Understanding Poverty in Uganda: Adding a Sociological Dimension, CSAE, Oxford.

Brockerhoff, M. P. 2000, ‘An Urbanizing World’, Population Bulletin, vol. 55, no. 3, p. 48.

Byerley, A. 2005, Becoming Jinja: The production of space and making of place in an African Industrial Town, Stockholm University, Stockholm.

Egbu, A., Antwi, A. et al. 2006, An economic assessment of the institution of land use planning in the cities of sub-Saharan Africa, Wolveharmpton RICS, p. 36. 
Government of Uganda (GoU) 1995, National Population Policy for Sustainable Development, Kampala, Government of Uganda.

Hoogvelt, A. M. M. 2001, Globalization and the postcolonial world: The new political economy of development, Johns Hopkins University Press.

Hulme, D. 2003, Conceptualizing Chronic Poverty, World Development Institute, Washington.

Inter-American Development Bank (IADB) and International Development Research Center (IDRC) 2002, Organizational Assessment: A framework for Improving Performance, IDRC, IADB, Ottawa, Washington.

IEG 2008, Using Knowledge to Improve Development Effectiveness: An Evaluation of World Bank Economic and Sector Work and Technical Assistance, 2000-2006, The World Bank, Washington DC.

ILRI and CBS 2002, Mapping Poverty in Kenya and Uganda, Nairobi, ILRI.

Jain, R. and Das, P. 2004, A Framework for Assessing Universal Service Obligations: A Developing Country Perspective, Ahmadabad, p. 15.

Kampala City Council (KCC) 1998, Kampala District Environmental Profile, NEMA, Kampala.

KCC 2001, Kampala District Environmental Profile, NEMA, Kampala.

KCC 2002, Kampala City Development Strategy, KCC, Kampala, p. 90.

KCC 2003, The Three-Year Development Plan, 2003/04-200/06, KCC, Kampala, p. 236.

KCC 2005, Kampala District 3 Year Development Plan, KCC, Kampala.

KCC 2008, Kampala District 3 Year Development Plan, KCC, Kampala.

KCC and World Bank 2000, City Development Strategy; A Situational Analysis, KCC, Kampala.

KCC and Belgian Technical Cooperation (BTC) 2008, Baseline Survey for the Kampala Integrated Environmental Management Project, Bwaise III, KCC, BTC, Kampala, p. 81.

McGill, R. 1988, 'Planning for Strategic Performance in Local Government', Long-range Planning, vol. 21, no. 5, pp. 77-84.

Ministry of Finance, Planning and Economic Development (MoFPED) 2000, Uganda Participatory Poverty Assessment Report: Learning from the Poor. MoFPED, Kampala, p. 150.

MoFPED 2005, Uganda Poverty Status Report, 2005, Government of Uganda, Kampala.

MoFPED 2007, Planned Urbanization for Uganda's Growing Population, State of Uganda Population Report 2007, Kampala, p. 93.

Ministry of Local Government (MoLG) 2001, Public Private Partnership for Urban Environment, MoLG, Kampala, p. 63.

Mukwaya, P., Sengendo, H. et al. 2008, The New Core Periphery Relations in Uganda: Institutional Responses in a Globalizing World. Inequality beyond Globalization: Economic changes and the dynamics of inequality, Midterm Conference of the International Sociological Association's Research Committee Economy and Society, Neuchatel, Switzerland, June 26-28, 2008, ISA.

Mukwaya, P. I., Lwasa, S. et al. 2007, Urban Agriculture for Sustainable Livelihoods in Uganda. State of Uganda's Population 2007, MoFPED, p. 93.

Nyakaana, J. B., Sengendo, H. et al. 2004, Urban Development, Population and the Environment in Uganda: The Case of Kampala City and its Environs, Kampala.

Peirce, N. R. and Johnson, C. W. 2008, Century of the City: No time to lose. New York, The Rockefeller Foundation. 
Rakodi, C. (ed.) 1997, The Urban Challenge in Africa: Growth and Management of its large cities. Tokyo, The United Nations University.

Rakodi, C. 2001, 'Forget planning, put politics first? Priorities for urban management in developing countries', JAG, vol. 3, no. 3, p. 15.

Raworth, K. 2007, 'Beyond aid as we know it', Development and Cooperation International Journal, vol. 48, no. 11, pp. 408-412.

REEV and KCC, et al. 2008, Baseline study for the Kampala Integrated Environmental Planning and Management Project, Kampala, Belgian Technical Cooperation, p. 81.

Rugadya, M. A. 2006, Situation Analysis Report and Action Plan for Kampala City Council: Kagugube 1 and Mbuya 1 Parishes. Cities Without Slums Sub-Regional Programme for Eastern and Southern Africa, Kampala, Kampala City Council, p. 71.

Samura, S. 2008, 'The pitfalls of Africa's aid addiction', BBC News, viewed 24 November, $<$ http://news.bbc.co.uk/2/hi/africa/7740652.stm>.

Sartre, J.-P. (ed.) 2001, Colonialism and Neocolonialism, Rutledge.

Seborer, S. J. 1974, Neocolonialism in Africa, New York, International Publishers.

Sengendo, H. 1997, 'Urbanization, Urban Governance and the environment: Critical conditions for formulating of an environmental strategy for Kampala-Uganda', Mawazo Journal, vol. 7, no. 2.

Simon, D. 1992, Cities, capital and development: African cities in the world economy, New York, Halstead.

TAHAL and Ministry of Works, Housing and Communications (MoWHC) 2005, Transport Master Plan for Greater Kampala Metropolitan Area. Kampala, Ministry of Works, Housing and Communications, p. 230.

UN-Habitat 2001, 'UN-Habitat Country Statistics Overview 2001', UN-Habitat, Kenya, $<$ http://www.unhabitat.org/list.asp?typeid=44\&catid=240>.

UN-Habitat 2005, Responding to the challenges of an urbanizing world, Nairobi, United Nations Human Settlements Programme, p. 38.

UN-Habitat 2006, 2006 Annual Report. Nairobi, United Nations Human Settlements Programme, p. 28.

UN-Habitat and ECA 2008, The State of African Cities - A framework for addressing urban challenges in Africa, Nairobi, United Nations Human Settlement Programme, p. 206.

United Nations Economic Commission for Africa (UNECA) 2007, Public Expenditure and Service Delivery in Africa: Perspectives on Policy and Institutional Framework. Addis Ababa, United Nations Economic Commission for Africa, p. 62.

World Bank Group (WBG) 2001, Carrying Out Community Contracting, World Bank Group, Washington. 